\title{
Direct Observations of Pedestrian Unsafe Crossing at Urban Australian Level Crossings
}

\author{
Teodora Stefanova ${ }^{1} \cdot$ Jean-Marie Burkhardt ${ }^{2} \cdot$ Christian Wullems $^{1}$. \\ James Freeman $^{1} \cdot$ Andry Rakotonirainy $^{1} \cdot$ Patricia Delhomme $^{2}$
}

Received: 22 March 2015/Revised: 17 May 2015/Accepted: 26 May 2015/Published online: 12 August 2015

(C) The Author(s) 2015. This article is published with open access at Springerlink.com

\begin{abstract}
The number of pedestrian victims at Australian and foreign level crossings has remained stable over the past decade and it continues to be a significant problem. To examine the factors contributing to pedestrians' unsafe crossing behaviours, direct observations were conducted at three black spot urban level crossings in Brisbane for a total of $45 \mathrm{~h}$ during morning and afternoon peak. In total, 129 pedestrians transgressed the active controls. More transgressions were observed at the crossings located in more populated suburbs in close proximity to large shopping centres and school zones, whereas the smallest number of transgressions were observed at the least populated locations. In addition to characteristics associated with the larger socio-economic area, the patterns of transgression could be associated with the properties of the existing safety equipment and the design of each level crossing (i.e. location of the platforms, number of rail tracks). Indeed, the largest number of crossed unoccupied but "at risk" rail tracks (where a train could have passed), was observed at the crossing with the least transgressions. Contrary to previous findings, younger adults were the most frequent transgressors. School children and elderly were most likely to transgress in groups. Potential directions for future research and more effective measures are discussed.
\end{abstract}

Teodora Stefanova

t.stefanova@qut.edu.au

1 Centre for Accident Research and Road Safety - Queensland, Queensland University of Technology, 130 Victoria Park Road, Kelvin Grove 4059, Australia

2 IFSTTAR, AME, LPC, 78000 Versailles, France

Editor: Baoming Han
Keywords Direct observations - Level crossings · Pedestrian behaviour - Transgressions

\section{Introduction}

Level crossings (LCs) are generally classified according to the protection systems with which they are equipped. Active LCs are equipped with automatic controls (e.g. red flashing lights, boom gates), whereas passive LCs are signalled with passive signs (e.g. "STOP"). At passive LCs road users cross when there is no visible approaching train, whereas active LCs assist or enforce users' movement (i.e. crossing is prohibited in the presence of activated controls). In Australia and Queensland in particular, LCs in urban areas can be equipped with special form of protection for pedestrians. The pedestrian flow is directed through a pedestrian corridor surrounded by mazes. Additional pedestrian lights and gates positioned on each end of the pedestrian maze activate on the approach of a train, regulating pedestrian traffic independently of vehicular road traffic. In the Brisbane area, this measure is particularly important at sites where access to a train station is provided via the LC. In this case, the rail tracks are likely to be separated by a middle island and pedestrian traffic can therefore be regulated separately on each side of the middle island hosting a train station or a platform.

While such additional measures that specifically target the improvement of pedestrian safety at LCs have been taken in Queensland, the number of collisions involving pedestrians compared to those involving motorists has remained stable in the last decade. A similar trend has also been observed in other countries $[1,2]$. In addition, more than half of the reported near-misses for 2011 in Queensland $(54 \%, N=253)$ were between a train and a pedestrian, noting that such data are likely to be underreported (i.e. these reports are provided by rail staff 
and therefore do not represent systematic counts) [3]. Collisions between rail vehicles and pedestrians are not only more likely to result in severe injuries and fatal consequences for victims (compared to other road crashes), but are also related to serious economic costs in the short and long term [4].

Each LC is unique, defined by the complex environment and surroundings comprising road and rail infrastructures and the actors involved in both systems [5]. Thus, safety constraints in this complex environment are subject to variability and are highly dependent on the dynamics of the larger system and the specificities of the crossing context. Building upon findings from a previous analysis of factors at play specific to LCs in Brisbane, the present paper presents the results from direct observations of pedestrian unsafe crossing behaviour at three actively protected black spot LCs [6]. Three sites with different, but common characteristics of the local Brisbane railway lines were selected to examine trends in pedestrian unsafe behaviour related to three main categories of factors.

After a brief review of the related literature, the study methodology is explained in detail and selected results are presented and discussed in context of previous findings and potential future research opportunities.

\section{Related Work}

A literature review on 23 papers related to pedestrian behaviour at LCs showed that, to date, a greater emphasis was directed towards studying the risky crossing behaviour of drivers as opposed to pedestrians' [6]. In most of the papers, the focus is on quantifying non-compliant behaviour according to legal norms-referred to as "transgressions", instead of looking at empirical evidence on the origins and the multiple factors contributing to unsafe pedestrian crossing behaviours. Seven of the studies included observation methods [1, 7-12]. Six of them were based on the analysis of video recordings of pedestrians crossing, and one (conducted in Australia) adopted a similar approach to ours, with observers coding the variables manually [7]. In the following paragraphs, main findings from observational and other studies are summarised in three large categories of factors that are likely to explain pedestrian unsafe crossing: (1) environmental and temporal characteristics of the crossing context; (2) pedestrian characteristics; and (3) social environment characteristics.

\subsection{Factors Related to the Physical Characteristics of the Environment and the Dynamics of the Crossing Context}

\subsubsection{Presence of Active Controls-Pedestrian Gates}

The presence of active pedestrian gates has been suggested as the most efficient type of controls by a number of authors [7, 13]. Metaxatos and Sriraj [1] observed that the odds of transgression decreased with the larger numbers of pedestrian gates at the LC compared to LCs equipped with only one pair of pedestrian gates (i.e. on one side of the crossing) or without gates. However, automatic gates introduce three separate moments before the final stage of control's activation, which could be associated with a suboptimal safety performance. In some cases, the presence of pedestrian gates was suggested to increase the so called "beating the gate tendencies" or the perception of control over the risk as long as the gate is not fully closed. In line with this assumption, Edquist, Hughes [7] noted that $50 \%$ of the observed transgressions (i.e.at LCs in Western Australia) occurred before the pedestrian gates had closed. Moreover, Metaxatos and Sriraj [1] observed more transgressions after the gates had started lowering and before they were in horizontal position than after. Transgressions in the riskiest moment (i.e. after the gates were fully lowered) were mainly observed after a train had already passed through the LC. Thus, the presence of pedestrian gates could be associated with an increase in risky crossing behaviours in the first moments of closure before the gates are fully closed (i.e. people assuming that "they can still make it safely on time"), but also after a train had passed through-often corresponding to the last moments of closure.

\subsubsection{Position and Number of Trains During Crossing}

Train position has been identified as a key factor influencing crossing decision [14]. One observational study demonstrated a significant effect of train position, such that the odds of transgression (versus safe crossing) were higher if crossing in front of an approaching train compared to behind an ongoing train [1]. Such behaviour could be explained by the lack of visibility of the approaching train or by a perception bias (i.e. a misjudgement of train speed or perception that the train is "far away"). Indeed, respondents in a survey conducted by Clancy, Dickinson [15] indicated that they had previously transgressed as they believed that they "had sufficient time to get across before the train reached the crossing" (p. 23). In relation to this, Clark, Perrone [16] have demonstrated that the estimation of the speed of large moving objects such as and specifically trains is likely to be erroneous. In their experimental simulation study, the same authors confirmed that consistent with Leibowitz' theory (1985), a visible approaching train is perceived to be moving slower that an approaching car and therefore could be a contributing factor towards pedestrians' low perception of risk.

While the risk of crossing in front of a second train has been largely demonstrated and discussed previously [10$13,15]$, it might not be as important in the current crossing 
context at LCs in Brisbane (2014), given that often a single track is operated by a separate set of active controls (pedestrian gates and lights) which deactivate allowing crossing soon after a train had passed. Nevertheless, the separately operated pedestrian corridors on both sides of a middle island could engender a high risk of crossing in front of a "second train", considering that controls on the opposite side of the middle island could activate anytime. Moreover, at middle islands, the presence of a stopped "at station" train could hinder vigilance and the perception of the activation of the second pair of controls if pedestrians are transgressing in a hurry to catch the stopped train.

\subsubsection{Platforms' Location}

To our knowledge, only Edquist, Hughes [7] have, to date, correlated unsafe crossing with the platforms' location visà-vis the rail tracks. According to the authors, pedestrians are more likely to transgress if the rail tracks are between the station platforms than if they are separated by a middle platform forcing thus pedestrians to cross more than one track at the time, to access either of the platforms.

\subsubsection{Temporal Characteristics of the Crossing Situation}

Morning and afternoon peak hours are associated with an increased number of pedestrian transgressions [14]. Nevertheless, while Edquist, Hughes [7] observed more transgressions in afternoon peak hours, Metaxatos and Sriraj [1] demonstrated that transgressions in different times of the day correspond to pedestrian traffic volumes particularly high in the morning and more widely distributed in the evening peak hours.

\subsection{Factors Related to Pedestrian's Characteristics and Motivations}

Two types of unsafe crossing behaviours can be distinguished according to pedestrian's intention. The term "violation" is frequently used to distinguish deliberate crossing in the presence of active controls from unintentional rule breaches that are referred to as "errors". In observational and other studies, young pedestrians are considered a high risk group of users who deliberately violate rules $[9,15]$. Their crossing behaviours have been associated with sensation seeking tendencies (thrill-seeking) or perception of control, compared to elderly for example. Furthermore, male pedestrians are associated with higher risk-taking tendencies than females, however such a trend was only confirmed by one observational study in which male transgressors were identified slightly more often than females $(59 \%)$ [7, 14]. Finally, according to Clancy, Dickinson [15] as well as Metaxatos and Sriraj
[1], motivations to deliberately transgress are associated with the given journey context (e.g. being in a hurry, avoiding missing the next train, being on time at work/ school). In contrast, errors are often associated with elderly pedestrians likely to experience hearing, motor or visual impairments $[6,8,9,14]$ or with distraction $[1,6]$.

\subsection{Factors Related to the Social Context of Crossing and Interactions Between Multiple Factors}

The presence of others has been shown to increase risktaking likelihood in previous observational studies. Accounting for differences in the size of pedestrian flow in and out of peak hours, Metaxatos and Sriraj [1] and Khattak and Luo [8] found that the number of transgressions increase with an increasing platoon size. According to the observations of Edquist, Hughes [7], crossing in groups could be more common among school children encouraging each other to deliberately transgress. Similarly, Khattak and Luo [8] showed that group violations increased in the presence of young children. More generally, being in a hurry or trying to avoid missing the next train were associated with an increased number of transgressions in the presence of a stopped at station train $[1,14]$.

While previous observational studies provide some interesting insights on factors likely to impact unsafe crossing the behaviours of pedestrians, the current knowledge-base remains limited. Moreover, the generalisability of previous findings is questionable when comparing different countries, territories, or even urban areas with different environmental characteristics. Differences between the results from previous studies or their interpretation could be explained by the variability of the adopted research designs, procedures (e.g. the periods of data collection, utilisation of recording devices) or data analysis methods. For instance, the number of observation sites varied between one [9, 10, 17] and ten [1]. In addition, data collection was conducted between 1997 and 2011 and could last from several days (10) to several months (two and nine). The longest data collection period spanned three consecutive years [8]. Most of the previous observational studies were conducted in the USA where LCs have similar, but not identical, design compared to Australian LCs. At American LCs, pedestrian gates are similar to those for vehicles prohibiting pedestrian crossing while lowered, whereas pedestrian gates in Brisbane close horizontally blocking the access through the path. Arguably, the existing findings are unlikely to reflect the "current" and broad pedestrian crossing context at LCs. They are unlikely to relate to LCs, where specific measures targeting pedestrian safety have been taken, as is the case in Queensland. 
Therefore, more in depth and context-centred research is needed.

\subsection{Rational for the Adopted Research Method and Research Question}

Compared to self-reported or crash data, direct observations allow for the detection of factors likely to impact decision-making without participants being necessarily aware of their influence (e.g. presence of others crossing unsafely). Providing more objective and descriptive information than any other methods, direct observations are fundamental for the investigation of pedestrian unsafe crossing, as a highly under-researched area.

This study is to our knowledge the most recently conducted in Australia, investigating multiple factors and their interactions that are likely to contribute to unsafe pedestrian crossing behaviours. Our main aim is to examine such factors and how they can be associated with different patterns of unsafe crossing, accounting for the specific crossing contexts of three typical LCs in Brisbane.

\section{Method}

\subsection{Choice of Observation Sites}

The first stage of site selection consisted in the review of the available indicators on unsafe crossing tendencies across LCs in Brisbane. According to the most recent data provided by the urban rail operator in Brisbane (Queensland Rail-QR), almost half of all reported near-misses with pedestrians for 2011 occurred at LCs on the same rail line, the Cleveland line (42\%). The second stage of site selection consisted in random direct observations at LCs black spot locations on the Cleveland line and other rail lines, during which information was collected on:

- Characteristics of the physical environment (e.g. number of rail tracks, location of the platforms and station, over bridge access and number of pedestrian corridors);

- Technical properties of the controls (e.g. progress of activation and duration of the active controls for pedestrians, presence of locking mechanisms on pedestrian gates);

- Characteristics of pedestrian-users (e.g. school children, dressed in business attire) and the most commonly adopted trajectories (i.e. in relation to pedestrian paths/ shortcuts).

Finally, additional information was collected from rail professionals (e.g. train drivers, station masters and transit officers) and QR safety experts who contributed to our decision to select three intersections adjacent to suburban train stations-all actively protected and part of the Cleveland rail line: Coorparoo, Cannon Hill, and Wynnum Central (Fig. 1). The selection of LCs that are part of the same rail line ensured that the observation sites had similar rail traffic characteristics and technical properties of the active controls (i.e. unlike the controls at other rail lines, the pedestrian gates on the Cleveland line do not lock when closed).

With a long history of reported accidents and the highest number of reported near-misses for 2011, the LC at Wynnum Central has been identified by QR as one of the worst black spots in Brisbane. By far, the largest percentage of near-misses reported on the Cleveland line occurred at Wynnum Central (41\%), compared to Coorparoo accounting for $8.5 \%$ and Cannon Hill accounting for $5 \%$, noting that the number of reported near-misses should only be considered as an approximate indication of the risk rate, given the reporting reliability issues that have previously been raised [18]. The most recent fatal collision with a pedestrian in Queensland occurred at Cannon Hill LC in January 2014, raising significant safety concerns among rail authorities. Finally, QR provided information about an increasing number of pedestrian violations at Coorparoo in recent years-2013/2014.

All three LCs are equipped with pedestrian gate systems consisting of an entry pedestrian gate that closes when activated (but can be pushed open from outside) and an emergency pedestrian gate that remains closed at all times. The emergency gate can be pushed open from inside in the case that a pedestrian is caught inside the tracks during a "closure" defined here as: the period from the onset until the cessation of the controls. Pedestrian lights and audible alarms are installed in each pedestrian gate system (Fig. 2).

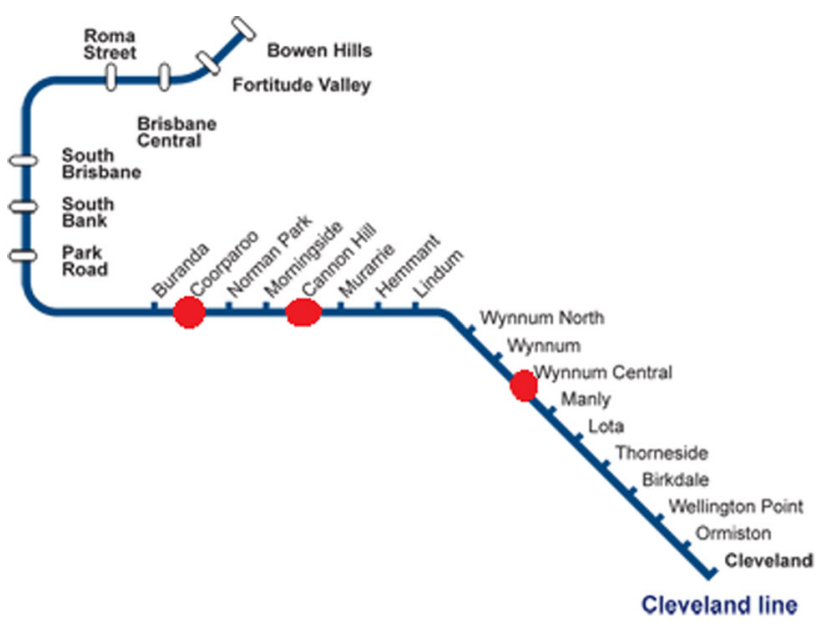

Fig. 1 The Cleveland rail line joining Cleveland—suburb of Redland city and with Brisbane the capital of the Australian state of Queensland. Part of the Queensland Rail City train network, the Cleveland line extends $37.3 \mathrm{~km}$ east-southeast from CBD (Brisbane Central Business District). In red are indicated the three selected LCs for observation sessions 


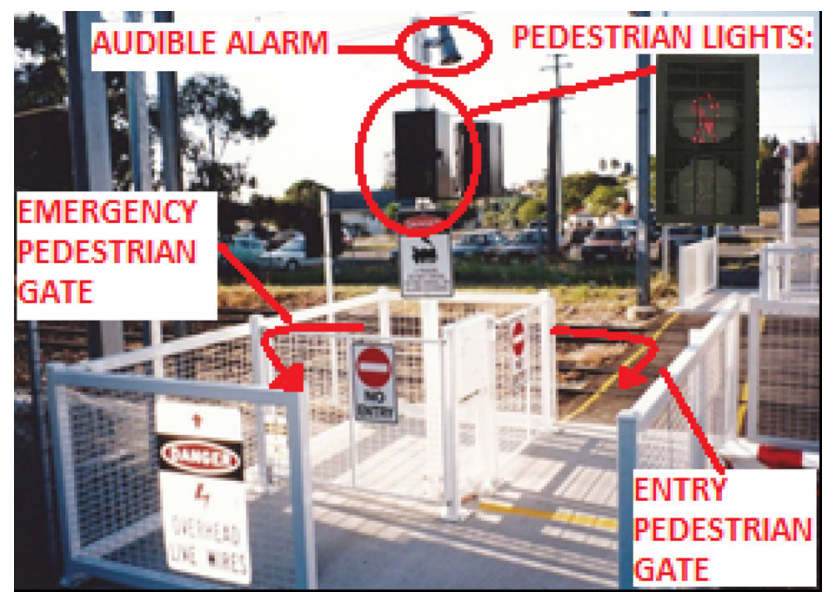

Fig. 2 Pedestrian gate system installed at the three LC observation sites

\subsection{Architectural Characteristics of each LC and the Corresponding Larger Socio-Economic Areas}

The suburbs of Wynnum Central and Coorparoo are more populated with 12,229 and 14,944 inhabitants (respectively) compared to Cannon Hill with a population of only 4507 inhabitants. All three LCs are in close proximity to schools and industrial zones. While Wynnum Central LC is positioned on a main road giving to a large shopping district, Cannon Hill and Coorparoo LCs are also in a close proximity to shopping centre zones.

\subsubsection{Wynnum Central Level Crossing and the Adjacent Train Station}

Wynnum Central LC has two rail tracks separated by a middle island giving access to the train station (Fig. 3). The middle (station) island comprises the two platforms typically giving access to passenger trains services in the direction to Cleveland-Outbound (i.e. Platform 1) and in the direction to Brisbane CBD-City (i.e. Platform 2). Two sets of pedestrian gate systems (i.e. one on the centre side and one on the residential side) activate simultaneously independently of the track or the direction of the approaching train. This implies that while an Outbound train (in direction to Cleveland) is stopped at stationpedestrian traffic is prohibited, whereas soon after a train in direction to the City had passed the LC (independently of whether the train is stationary or not), pedestrian traffic is allowed. A third set of pedestrian gate system regulates traffic on the opposite station road side.

The pedestrian corridor on the station road side is approximately $16 \mathrm{~m}$ long $(8 \mathrm{~m}$ on both sides of the middle island) and the opposite station side pedestrian corridor is approximately $14 \mathrm{~m}$ long.

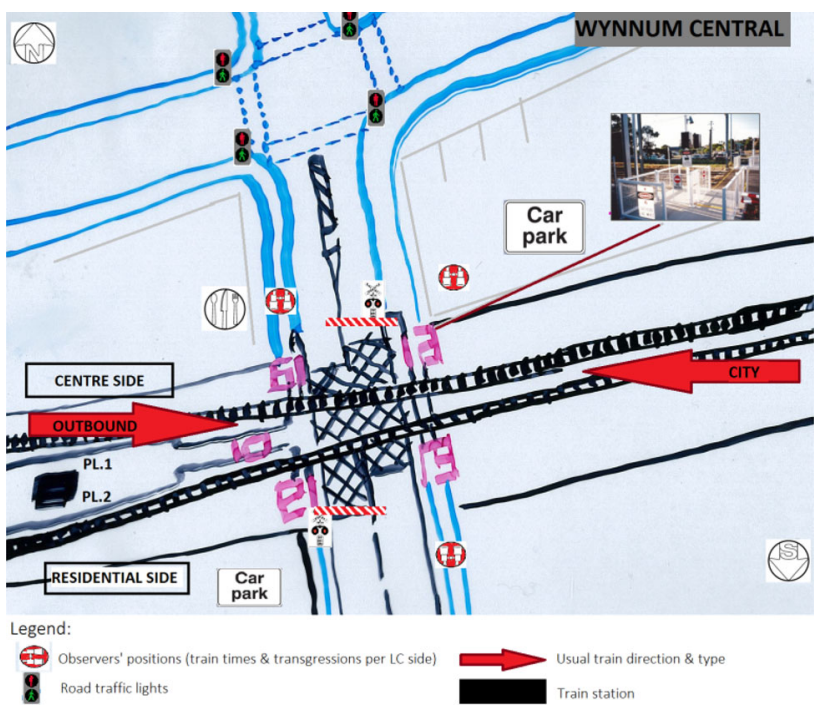

Fig. 3 Bird's eye graphic view of Wynnum Central LC based on a Google Earth photograph. Source: Google Earth (2009) corresponding to $151 \mathrm{~m}$ eye altitude

Two QR car parks are provided for users of the train station: one North and one South of the LC. A third car park, further West in the Centre side of the LC provides access to the station through an over bridge (not illustrated on Fig. 1).

\subsubsection{Cannon Hill}

Cannon Hill LC has three rail tracks separated by a middle island (Fig. 4). The station is external to the LC giving access to Platform 2 where typically passenger train services run in the direction to the City. Platform 1 located on the middle island typically gives access to Outbound trains.

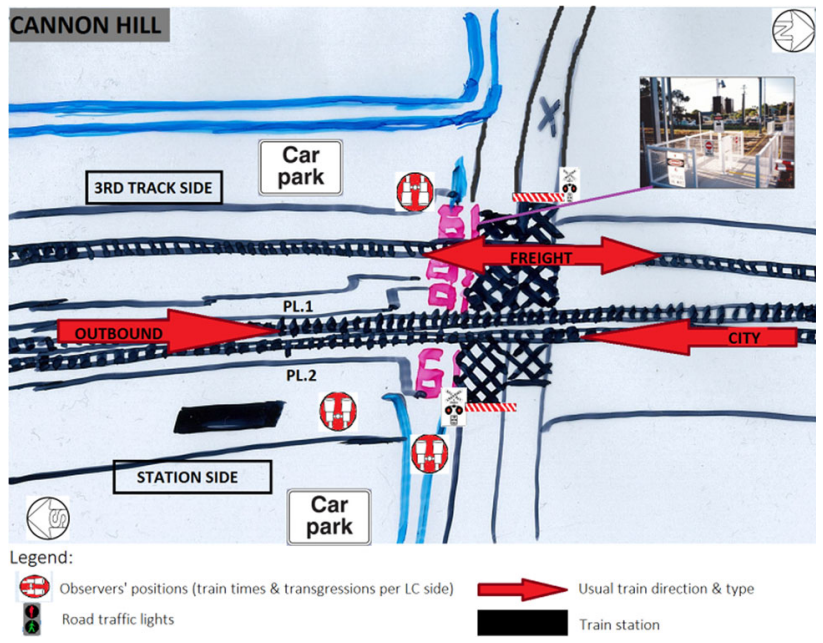

Fig. 4 Bird's eye graphic view of Cannon Hill LC based on a Google Earth photograph. Source: Google Earth (2009) corresponding to $151 \mathrm{~m}$ eye altitude 
The third track serves only freight trains passing in both directions. Two sets of pedestrian gate systems activate separately prohibiting pedestrian traffic on either side of the middle island. Thus, pedestrian traffic is prohibited on the 3rd track side only during the rare passage of freight trains which do not follow a strict timetable. Similarly to Wynnum Central, when an Outbound train is stopped at the station pedestrian traffic is prohibited, whereas as soon as a City train has passed through the LC, pedestrian traffic is permitted. There is not a pedestrian corridor on the opposite station road side.

The pedestrian corridor is approximately $20 \mathrm{~m}$ long $(7.50 \mathrm{~m}$ on the $3 \mathrm{rd}$ track side and $12.50 \mathrm{~m}$ on the station side of the middle island).

There are a number of primary schools on each side of the LC and a shopping centre is east from the LC (station side). Two QR car parks are provided for station users on both sides of the LC. An over bridge further south connects the two platforms and provides access to the middle island from the 3rd track side car park.

\subsubsection{Coorparoo}

Coorparoo LC (Fig. 5) has three rail tracks separated by a middle island giving access to the train station. The middle (station) island comprises the two platforms typically giving access to passenger Outbound (i.e. Platform 2) and City (i.e. platform 1) services. The third track serves only freight trains passing in both directions. Two sets of pedestrian gate systems activate separately prohibiting pedestrian traffic on either side of the middle island. Thus, every time an Outbound service is passing, pedestrian traffic through the freight track is also prohibited and inversely, every time a freight train is expected, the crossing of the Outbound rail track is prohibited. Similarly

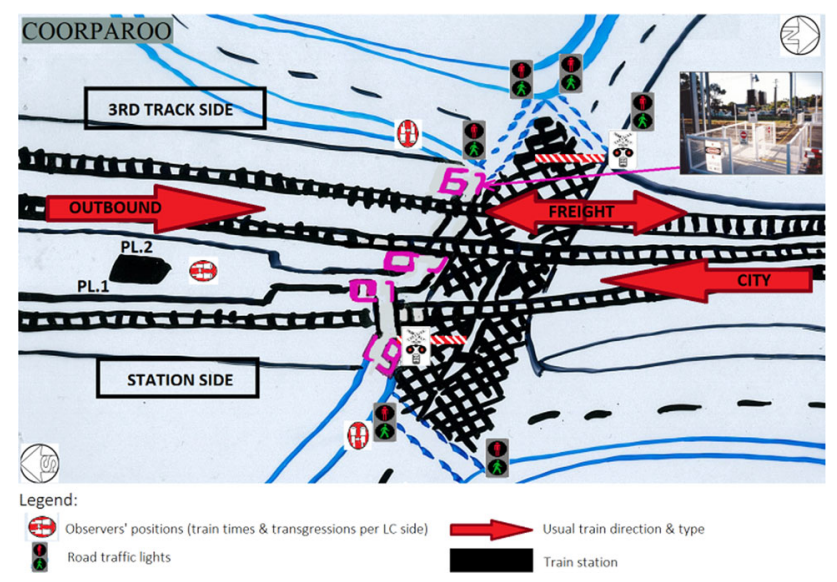

Fig. 5 Bird's eye graphic view of Coorparoo LC based on a Google Earth photograph. Source: Google Earth (2009) corresponding to $151 \mathrm{~m}$ eye altitude to the other two LCs, pedestrian traffic is prohibited while there is a stopped Outbound train at station, and renewedas soon as a City train has passed the crossing. There is not a pedestrian corridor on the opposite station road side.

The pedestrian corridor is approximately $26.5 \mathrm{~m}$ long (17.5 $\mathrm{m}$ on the $3 \mathrm{rd}$ track side and $9 \mathrm{~m}$ on the station side of the middle island). There are a number of schools mostly East from the LC (station side) and a shopping centre in the same direction.

\subsection{Research Design and Participants}

\subsubsection{Choice of Time Frames for Morning and Afternoon Observation Sessions}

To capture the busiest pedestrian traffic periods, observation sessions took place at morning and afternoon peak hours, respectively, from 7 am to 9.30 am and from $3 \mathrm{pm}$ to $5.30 \mathrm{pm}$. They were conducted systematically every (working) Monday, Wednesday and Thursday in three consecutive weeks, thereby avoiding the collection data associated with specific social events likely to take place on weekends or public holidays. This organisation of the observation shifts allowed the conduct of one morning and one afternoon session at one of the three LCs on each of the 3 week days. All three LCs were visited during each week of observations following a random order.

Observations started in the first week after school holidays as students were among the targeted groups of potentially "at risk" pedestrians. The hours of the observation shifts were also planned in accordance with the crossing time frames of various socio-demographic classes (e.g. construction workers, office workers, school children and pensioners) and corresponded to the typical start/finish working (school) hours.

\subsubsection{Observers}

Five researchers from the Centre for Accident Research and Road Safety Queensland (CARRS-Q) were trained by the lead researcher for data collection and entry, during a week of pre-observation. To enhance familiarity, pre-observations took place at all LC sites and each observer was trained to code data related to two main observer's roles: (1) coding transgressions and (2) coding train times. Two “Transgressions" observers per session coded the personal and crossing characteristics of transgressors. They were positioned close to the pedestrian corridors on each side of the LC and coded: the gender and the approximate age of transgressors; the adopted crossing trajectory; the number of people crossing in groups; and the number of people waiting for the controls to deactivate (compliant crossing behaviour). One other "Train times" observer per session 
was in charge of coding the exact time $(\mathrm{hh} / \mathrm{mm} / \mathrm{sec})$ when a train has reached the LC, stopped or left a station as well as the number and types of trains per closure and their respective direction and platform. Depending on the site, "Train Times" observers were positioned at a station (Figs. 4, 5) or at a nearby car park (Fig. 3). The variables related to Closure characteristics (e.g. the exact hour of each control's activation) were taken either by observers coding train times (Fig. 3) or by observers coding transgressions-where the controls on the two sides of the middle island activate separately (Figs. 4, 5).

\subsection{Material}

Observation sheets and chronometers (on android mobile devices) were used for data collection. Variables related to each closure were coded on a separate sheet independently of whether a transgression took place or not. A closure identification number was coded on each observation sheet, facilitating the synchronisation of data between observers during data entry. All observers were equipped with a set of observation sheets in the form of a notebook.

\subsubsection{Transgression Sheets}

Transgression sheets (Appendix 1) had two main parts. In the first part, a rough plan of each LC's platforms and pedestrian corridors served to trace the trajectory of transgressions. The same method was used to code the number of people at each angle of the LC who did not transgress (compliant crossing group) at the end of each closure. It is important to note that where pedestrians waiting at the angle exceeded ten, the counts should be considered approximate due to poor visibility.

In the second part of the sheet were coded demographic and other characteristics of the pedestrians who transgressed: gender-male versus female; approximate agebaby/toddler (0-4 years old) versus school children (5-15 years old) versus young adult/teenager (16-30 years old) versus older adult (30-70 years old) versus elderly (70+ years old); exact time of transgression-exact hour when the pedestrian stepped on the LC platform $(\mathrm{hh} / \mathrm{mm} /$ $\mathrm{sec})$; status of controls' activation at the moment of transgression-Moment 1 (pedestrian lights flashing) versus Moment 2 (pedestrian gates closing) versus Moment 3 (pedestrian gates fully closed). It is worth noting that the time difference between the three moments is typically $8 \mathrm{~s}$, meaning that $16 \mathrm{~s}$ after the activation of the pedestrian lights, the pedestrian gates are fully closed. In addition, observers were trained to identify a minimum set of variables related to the description of the transgressors: crossing pace-walking versus speeding/running; social influences-crossing alone vs. in group, journey purpose- on the way to catch a train (yes vs. no, where possible to identify).

\subsubsection{Train and Closure Times Sheets}

Train time sheets (Appendix 2) were used to code the following variables: order of train passing at the $L C$ (the order of arrival at the LC or at the station); number of platform; direction-City versus Cleveland; type of trainstopping at station versus express, independently of whether it was an empty service, a train that does not serve the station or else, a freight train (i.e. typically long trains passing on the 3rd track at Cannon Hill and Coorparoo); hour of train passing - three times were taken for stopping trains (arrives at LC vs. stops at station vs. leaves station) and one for express trains-the hour it arrived at the LC.

Closure times were coded by multiple observers at each LC and included the following variables: start closurehour of the activation of the pedestrian flashing lights corresponding to Moment I ( $\mathrm{hh} / \mathrm{mm} / \mathrm{sec})$; gate closinghour when the pedestrian gate starts closing corresponding to Moment II ( $\mathrm{hh} / \mathrm{min} / \mathrm{sec})$; gate closed-hour when the pedestrian gate is fully closed corresponding to Moment III (hh/min/sec); end closure-hour when the pedestrian lights deactivates $(\mathrm{hh} / \mathrm{min} / \mathrm{sec})$. To avoid mistakes in data entry, these variables were entered on the observation sheet only after the end of each closure, given that the times remained recorded on the chronometer screen.

\subsection{Procedure}

Having obtained permission from QR to conduct this study on their property, all visits of LC sites were preceded by safety instruction sessions for observers. Observers were in contact with rail staff at all times. Pre-observations were conducted for one week prior to the actual observations. During this period, the first researcher familiarised the four assistant observers with the objectives of the study, the coding process and the specificities related to each LC site. The actual observation sessions were conducted by three of the five researchers each. The larger number of observers allowed the shuffling of shifts and thus to avoid fatigue related issues. Each observation session was preceded by a synchronisation of all chronometers. No breaks were taken during observations. It is likely that the presence of observers was noticed by pedestrians even though the most discrete positions were selected considering safety procedures (e.g. remain in a significant distance from roadside) and the visibility of the targeted variables. After the end of the sessions, all observers were debriefed by the first researcher. Questions around data were discussed and resolved. All observers together started data entry shortly after the end of each session using a laptop and pre- 
established Microsoft Excel sheets. Data entry took approximately $1 \mathrm{~h}$ and $30 \mathrm{~min}$. This study was approved by the university ethics committee.

\subsection{Collected Data and Statistical Analysis}

The data were collected during three consecutive weeks between 28 April 2014 and 15 May 2014, representing a total of $45 \mathrm{~h}$ of observations across all sites. In total 438 closures were observed, each lasting from $12 \mathrm{~s}$ at Wynnum Central, where crossing through the two passenger services tracks is prohibited simultaneously, to $3 \mathrm{~min}$ and $51 \mathrm{~s}$ at Coorparoo, where the two passenger services tracks close autonomously. There was not a significant difference between the average duration of closures at all three LCs $(M=75.06 \mathrm{~s}, S D=35.62 \mathrm{~s}), F(2,435)=1.23, \mathrm{~ns}$. It should be noted that during the last afternoon observation session at Wynnum Central, a cancellation of all train services following an incident resulted in a smaller number of closures and a higher volume of passengers leaving the train station (after having disembarked a City train). Nevertheless, the number of closures at each site was relatively constant over the three days of observation, $\chi^{2}$ (4, $N=438)=2.17$, ns. One "false closure" was observed at Cannon Hill during which a train did not pass. Instead, both sides of the LC were closed for maintenance during $21 \mathrm{~s}$, noting that no transgression took place.

Most of the closures were for the passage of a singletrain $(84 \%)$, two trains passed in $15 \%$ of the closures, and only on three occasions did three trains pass during the same closure (Table 1). Because of this small number of three train closures, they were considered together with two train closures for the remainder of the analysis. Regarding the types of train passing during closure, most of the closures included at least one stopping train, accounting for $76 \%$ of the single-train closures and for $93 \%$ of the multiple trains closures (Table 1). Closures involving only express trains represented $21 \%$ of all 437 closures with passing trains. The distribution of number and types of trains passing during closures did not differ according to the three LCs (Fisher, ns.).
For the analysis of the collected data, a series of Chisquare tests $\left(\chi^{2}\right)$ were performed to test the significance effect between two discrete variables. Fisher's exact test was used for contingency tables that contain small expected values $(<5)$ in more than $20 \%$ of the cells (i.e. only $p$ value is reported). Cramers' $V^{2}$ statistic was used to report the strength of association between discrete variables typically applied to $2 \times n$ tables, which is conventionally considered to be low if $<0.04$, medium if between 0.04 and 0.16 , and high if $>0.16$ [19]. Relative Deviations (RDs) were used to inform on the strength of association between the modalities of the two discrete variables. Relative deviations are calculated on the basis of the comparison between the observed and expected frequencies in each cell. By convention, there is a high positive or negative association when the absolute $\mathrm{RD}$ value is $>0.20$. Only associations $>0.10$ are described in the results section. Finally, analysis of variance tests (ANOVA) and correlations were used to test the effects on continuous variables. Post-hoc tests using Bonferroni correction were used to examine the relationships between the modalities of continuous variables (only $p$ value is reported where the means are presented in tables).

\section{Results}

\subsection{Frequency and Proportions of Observed Transgressions at the Three LC Sites}

As per Table 2, the largest number of transgressions was observed at Wynnum Central and Coorparoo accounting for, respectively, 46.5 and $41.9 \%$ of all 129 observed transgressions across the three LC sites. In contrast, Cannon Hill was characterised with a low number of transgressions representing only $11.6 \%$ of all transgressions. Twenty percent of all closures included at least one person in transgression. The proportion of closures with at least one transgression varied significantly between sites, $\chi^{2}(2$, $N=438)=28.03, p<0.000$, with the largest ratio of closures with transgressions observed at Wynnum Central
Table 1 Type of trains observed during closures

\begin{tabular}{|c|c|c|c|c|c|c|c|c|}
\hline & \multicolumn{2}{|c|}{ One train closures } & \multicolumn{2}{|c|}{ Two train closures } & \multicolumn{2}{|c|}{ Three train closures } & \multicolumn{2}{|c|}{ Total } \\
\hline & $\mathrm{N}$ & $\%$ & $\mathrm{~N}$ & $\%$ & $\mathrm{~N}$ & $\%$ & $\mathrm{~N}$ & $\%$ \\
\hline Express train & 87 & 92.5 & 7 & 7.4 & 0 & 0 & 94 & 100 \\
\hline Stopping train & 283 & 94.6 & 16 & 5.3 & 0 & 0 & 299 & 100 \\
\hline Both & 0 & 0.0 & 41 & 93.1 & 3 & 6.8 & 44 & 100 \\
\hline Total & 370 & 84.6 & 64 & 14.6 & 3 & 0.6 & 437 & 100 \\
\hline
\end{tabular}

Legend The false closure" has been omitted in the table as not implying a train passage 
Table 2 Counts and percentages of closures with at least one pedestrian in transgression per LC site

\begin{tabular}{|c|c|c|c|c|c|c|c|}
\hline & \multirow{2}{*}{$\begin{array}{l}\text { Closures } \\
\mathrm{N}\end{array}$} & \multicolumn{2}{|c|}{ Closures with transgression } & \multicolumn{2}{|c|}{ Transgressions } & \multicolumn{2}{|c|}{ Transgressions per closure } \\
\hline & & $\mathrm{N}$ & $\%$ & $\mathrm{~N}$ & $\%$ & $\begin{array}{l}\text { Among all } \\
\text { closures } \\
M(S D)\end{array}$ & $\begin{array}{l}\text { Among closures } \\
\text { with transgression } \\
\text { M (SD) }\end{array}$ \\
\hline Wynnum central & 117 & 40 & 34 & 60 & 46.5 & $0.51(0.87)$ & $1.97(1.21)$ \\
\hline Cannon hill & 149 & 13 & 9 & 15 & 11.6 & $0.10(0.36)$ & $1.40(0.83)$ \\
\hline Coorparoo & 172 & 35 & 20 & 54 & 41.9 & $0.32(0.73)$ & $2(0.95)$ \\
\hline Total & 438 & 88 & 20 & 129 & 100 & & \\
\hline
\end{tabular}

and the least-at Cannon Hill, the strength of association between the variables being moderate, $V^{2}=0.06$.

Looking into the number of pedestrians in transgression during the same closure, a maximum of five were observed at Wynnum Central and four at Coorparoo, both on a single occasion. Most commonly, between one and three transgressors were observed per closure with no significant difference in the distribution across the three LCs, Table 2 (Fisher, ns.).

\subsection{Transgressions Associated with the Physical Characteristics of the Environment and the Specific Crossing Context}

\subsubsection{Transgressions According to the Status of the Controls (Moment of Crossing)}

Comparing transgressions according to the three moments of controls' activation, more than half were observed during the first seconds after the activation of the pedestrian lights (Moment 1); almost one quarter were observed in the riskiest moment while the gates were closed (Moment 3); and the smallest amount occurred in Moment 2 while the gates were in the process of closing (Table 3). The distribution of transgressions according to the moments of crossing differed significantly among the LC sites (Fisher, $p<0.01$ ), with an intermediate strength of association between the variables, $V^{2}=0.08$. The analysis of the RDs revealed that Cannon Hill was particularly associated with crossing in Moment 1, Coorparoo with crossing in Moment 2 and Wynnum Central with crossing in Moment 3.

\subsubsection{Transgressions According to Train's Position}

According to the position of the train during a transgression, only one pedestrian was observed crossing in front of a stopped at station train and a small number of transgressions were observed behind a passing (express) train. These crossing situations were merged as "other train position" modality for further analysis. Globally, the large
Table 3 Counts and percentages of transgressions according to the status of active controls

\begin{tabular}{|c|c|c|c|c|c|c|}
\hline & \multicolumn{2}{|c|}{$\begin{array}{l}\text { Moment } 1 \\
\text { ped. Lights }\end{array}$} & \multicolumn{2}{|c|}{$\begin{array}{l}\text { Moment } 2 \\
\text { gates closing }\end{array}$} & \multicolumn{2}{|c|}{$\begin{array}{l}\text { Moment } 3 \\
\text { gates closed }\end{array}$} \\
\hline & $\mathrm{N}$ & $\%$ & $\mathrm{~N}$ & $\%$ & $\mathrm{~N}$ & $\%$ \\
\hline Wynnum Central & 32 & 53.3 & 6 & 10 & 22 & 36.6 \\
\hline Cannon Hill & 13 & 86.6 & 2 & 13.3 & 0 & 0 \\
\hline Coorparoo & 30 & 55.5 & 15 & 27.7 & 9 & 16.6 \\
\hline Total & 75 & 58.1 & 23 & 17.8 & 31 & 24 \\
\hline
\end{tabular}

Legend Moment 1-from activation of pedestrian lights until activation of pedestrian gate; Moment 2-from activation of pedestrian gate until full closure (period of closing); Moment 3-from the full closure of pedestrian gate until deactivation of pedestrian lights

majority of transgressions (85\%) occurred in front of an approaching train (Table 4). However, there was a significant difference in the number of transgressions according to train's position between the three sites (Fisher, $p<0.05$ ), with an intermediate strength of association between the two variables, $V^{2}=0.05$. The estimation of the RDs showed that among the three sites, Wynnum Central was the one preferentially associated with transgressions behind a stopped train and in "other positions", all of these situations characterised by the presence of a visible train.

\subsubsection{Transgressions According to Crossing Trajectory and LC Angle}

Looking into the adopted trajectories during transgressions (Table 5), the largest proportion of pedestrians were observed on their way towards a middle island $(71.3 \%)$, whereas crossing out of a middle island (15.5\%) and just crossing the road $(13.2 \%)$ were less frequently observed trajectories during transgressions. A Fisher's exact test showed a significant difference in the adopted trajectories between the three LCs (Fisher, $p<0.001$ ). The association between the modalities of the variables was moderate $\left(V^{2}=0.08\right)$, suggesting that Cannon Hill, contrary to the other two LCs, was associated with the two less common 
Table 4 Counts and percentages of transgressions according to train position across the three LCs

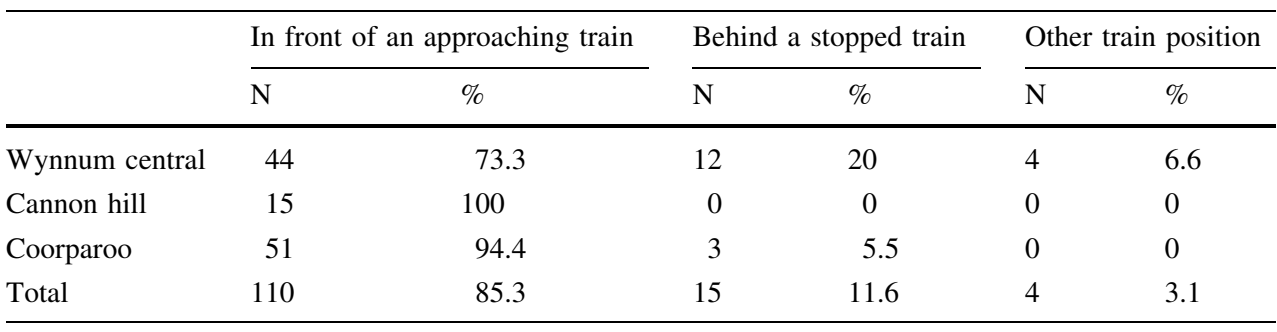

Legend the category "Other train position" included (1) transgressing behind an express passing train, and (2) transgressing in front of a stopped at station train

Table 5 Counts and percentages of transgressions according to the adopted crossing trajectory

\begin{tabular}{lllllll}
\hline & $\begin{array}{l}\text { To middle island } \\
\text { (train station) }\end{array}$ & $\begin{array}{l}\text { Out of middle island } \\
\text { (train station) } \\
\%\end{array}$ & $\begin{array}{l}\text { Just crossing } \\
\text { the road } \\
\text { N }\end{array}$ & $\begin{array}{l}\text { To middle island } \\
\text { (train station) }\end{array}$ & $\begin{array}{l}\text { Out of middle island } \\
\text { (train station) } \\
\%\end{array}$ & $\begin{array}{l}\text { Just crossing } \\
\text { the road } \\
\mathrm{N}\end{array}$ \\
\hline Wynnum Central & 46 & 76.6 & 6 & 10.0 & 8 & 13.3 \\
Cannon Hill & 4 & 26.6 & 8 & 53.3 & 3 & 20.0 \\
Coorparoo & 42 & 77.8 & 6 & 11.1 & 17 & 11.1 \\
Total & 92 & 71.3 & 20 & 15.5 & 13.2 \\
\hline
\end{tabular}

trajectories (i.e. out of a middle island or just crossing the road).

The patterns of the adopted trajectory could be associated with the specific design of each LC. To examine further these patterns, Fig. 6 illustrates graphically the distribution of the transgressions among the three LCs, according to the three trajectories and the crossing angle. While at Wynnum Central and Coorparoo the majority of transgressions occurred on the way to a middle island (i.e. corresponding to the emplacements of a train station), pedestrians at Wynnum Central adopted visibly more variable trajectories, particularly when crossing from the Centre side of the LC (i.e. diagonal through the road and crossing in the middle of the road). In contrast, at Coorparoo more transgressions were observed from the Station side of the LC and none on diagonal which could be explained by the absence of pedestrian path on the opposite station side. However, the only transgression on a diagonal out of a station line was observed at the same LC, which could be associated with an impatience to wait at the adjacent road traffic lights. The majority of transgressions at Cannon Hill out of the middle island or just crossing the road seemed to be associated with accessing the train station positioned externally to the rail tracks or the large car park adjacent to the Station side of the LC.

\subsubsection{Transgressions According to the Number of Crossed Tracks}

A significant difference was found between the number of rail tracks crossed while transgressing between the three LCs, such that transgressions at Wynnum Central implied the least number of crossed tracks $(M=1.15, S D=0.36)$, followed by Coorparoo $(M=1.54, S D=0.66)$ and the largest number of crossed rail tracks per transgression was observed at Cannon Hill $(M=2.13, S D=0.51), F(2$, 126) $=23.06, p<0.000, \eta^{2}=0.26$, the difference comparing all three sites being significant at $p<0.000$.

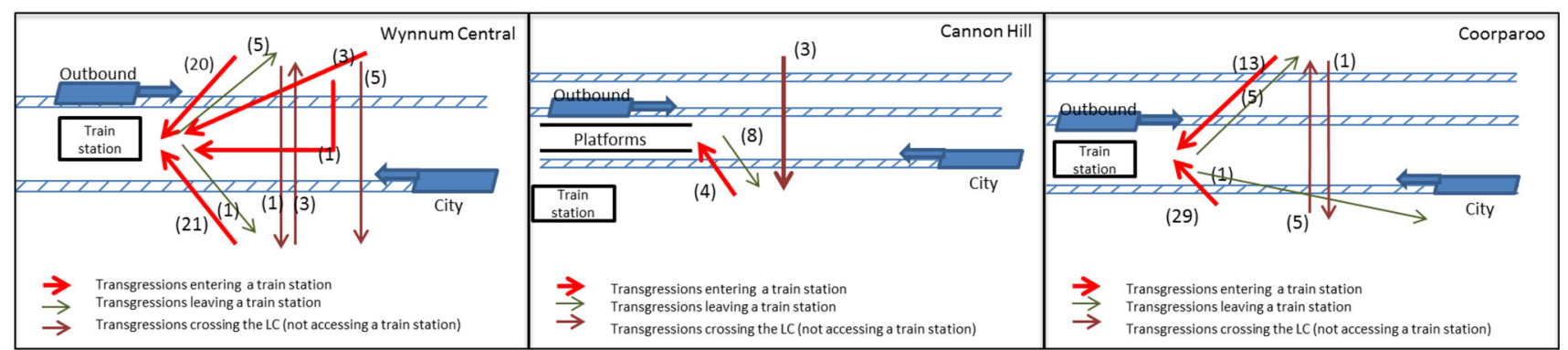

Fig. 6 Patterns of transgressions according to LC angle at each LC 
To investigate further the risk-taking tendencies accounting for the number of crossed tracks, an additional variable was computed corresponding to the number of crossed "Unoccupied tracks". This variable corresponded to the counts of crossed tracks where a train could have passed during the closure given that crossing through the same track after a train had already passed is not associated with a real risk of being hit by a train. As shown in Table 6, more than half of the pedestrians across all three LCs crossed at least one unoccupied track $(48+4.6 \%)$. Here again, a significant difference was found in the number of crossed unoccupied tracks according to the LC (Fisher, $p<0.01$ ), with an intermediate association between the variables $\left(V^{2}=0.05\right)$. The estimation of the RDs revealed different risk-taking patterns across the three sites. Consistent with the total number of crossed tracks during transgressions, Wynnum Central was moderately associated with crossing one unoccupied track, whereas Cannon Hill was at the same time moderately associated with the crossing of one and strongly associated with the crossing of two unoccupied tracks. In contrast, Coorparoo was associated at the same time with crossing none and two unoccupied tracks.

\subsubsection{Transgressions According to Time of the Day}

More than two thirds of the closures with at least one transgression took place in morning peak hours $(69.7 \%)$, $\chi^{2}(1, N=438)=9.67, p<0.01$ (Table not provided). Similarly, two thirds of all transgressions were observed in morning peak hours (Table 7). Although systematically

Table 6 Counts and percentages of crossed unoccupied tracks during transgressions at the three LCs

\begin{tabular}{|c|c|c|c|c|c|c|}
\hline & \multicolumn{2}{|c|}{ None } & \multicolumn{2}{|c|}{1 Track } & \multicolumn{2}{|c|}{2 Tracks } \\
\hline & $\mathrm{N}$ & $\%$ & $\mathrm{~N}$ & $\%$ & $\mathrm{~N}$ & $\%$ \\
\hline Wynnum central & 27 & 45 & 33 & 55 & 0 & 0 \\
\hline Cannon hill & 4 & 26.6 & 8 & 53.3 & 3 & 20 \\
\hline Coorparoo & 30 & 55.5 & 21 & 38.8 & 3 & 5.5 \\
\hline Total & 61 & 47.2 & 62 & 48 & 6 & 4.6 \\
\hline
\end{tabular}

Table 7 Counts and percentages of transgressions according to time of the day (morning vs. afternoon peak hours)

\begin{tabular}{|c|c|c|c|c|}
\hline & \multicolumn{2}{|c|}{ AM (7-9.30) } & \multicolumn{2}{|c|}{ PM (3-5.30) } \\
\hline & $\mathrm{N}$ & $\%$ & $\mathrm{~N}$ & $\%$ \\
\hline Wynnum central & 36 & 27.9 & 24 & 18.6 \\
\hline Cannon hill & 12 & 9.3 & 3 & 2.3 \\
\hline Coorparoo & 44 & 34.1 & 10 & 7.8 \\
\hline Total & 92 & 71.3 & 37 & 28.7 \\
\hline
\end{tabular}

more transgressions were observed in the morning than in the afternoon, there was a significant difference between the three sites according to the time of day, $\chi^{2}$ (2, $N=129)=7.04, p<0.05$, with an intermediate strength of association between the variables $V^{2}=0.05$. The estimation of the RDs showed that unlike the two other sites, Wynnum Central is more associated with transgressions in the afternoon, (Table 7).

\subsubsection{Transgressions According to Exposure}

In total, 2446 pedestrians were counted crossing compliantly during all observed closures (i.e. closures with and without transgressions). The number of pedestrians crossing compliantly per closure varied between 0 and 77 $(M=5.58, S D=8.13)$. As indicated in Table 8 , the largest number of pedestrians crossing compliantly per closure was observed at Wynnum Central $F(2,435)=23.17$, $p<0.000, \eta^{2}=0.10$. Also, more compliant crossings were observed during the afternoon closures, $F(1$, 436) $=4.09, p<0.05, \eta^{2}=0.02$. The interaction between the two variables (Sites * Time of the day) was also significant, $F(2,432)=10.14, p<0.000, \eta^{2}=0.05$, suggesting that the largest number of pedestrians crossing compliantly was counted at Wynnum Central compared to the other two LCs $(p<0.000)$. This result could be related to the exceptional cancellation of the train services. In contrast, there was a similar number of people in the morning peak hours at the most and least populated LCs (i.e. respectively Coorparoo and Cannon Hill).

The 129 observed transgressors represented around $5 \%$ of all people crossing during the closures. Accounting for compliant crossing, at Wynnum Central was observed the highest percentage of transgressors in the afternoon peak hours and at Coorparoo-the highest percentage of transgressions in the morning peak hours (Table 8).

\subsection{Transgressions Associated with Pedestrians' Characteristics and Motivations}

\subsubsection{Transgressions According to Demographics}

All 129 transgressors were distributed among five approximate age groups. Two babies (toddlers) were merged for further analysis with the young adults group as they were accompanied by adults of this age group. Male transgressors were slightly more numerous than females, and young adults were the most numerous among all age groups, $\chi^{2}(3, N=129)=2.59$, ns., (Table 9). Similarly, there was not a significant difference in the number of transgressors according to age (Fisher, ns.) or gender $\mathrm{p}\left[\chi^{2}\right.$ $(2, \quad N=129)=1.41$, ns.] between the three LCs (Table not presented). 
Table 8 Counts of pedestrians crossing compliantly and proportion of transgressions per LC

\begin{tabular}{|c|c|c|c|c|c|c|c|c|c|c|c|}
\hline & \multicolumn{6}{|c|}{ Compliant crossing/Closures } & \multicolumn{5}{|c|}{ Transgressions/Compliant crossing } \\
\hline & \multicolumn{2}{|c|}{ AM (7-9.30) } & \multicolumn{2}{|c|}{ PM (3-5.30) } & \multicolumn{2}{|c|}{ Total $(\mathrm{AM}+\mathrm{PM})$} & \multicolumn{2}{|c|}{ AM (7-9.30) } & \multicolumn{2}{|c|}{ PM (3-5.30) } & \multirow{2}{*}{$\begin{array}{l}\text { Total }(\mathrm{AM}+\mathrm{PM} \\
\%\end{array}$} \\
\hline & $\mathrm{N}$ & M & $\mathrm{N}$ & M & $\mathrm{N}$ & M & $\mathrm{N}$ & $\%$ & $\mathrm{~N}$ & $\%$ & \\
\hline Wynnum Central & $425 / 68$ & 6.25 & $663 / 49$ & 13.53 & 1088 & 9.29 & $36 / 425$ & 8.47 & $24 / 663$ & 3.49 & 3.61 \\
\hline Cannon hill & $330 / 80$ & 4.12 & $277 / 69$ & 4.01 & 607 & 4.07 & $12 / 330$ & 3.63 & $3 / 277$ & 1.32 & 2.47 \\
\hline Coorparoo & $420 / 93$ & 4.52 & $331 / 79$ & 4.19 & 751 & 4.37 & $44 / 420$ & 10.47 & $10 / 331$ & 3.02 & 7.19 \\
\hline Total & $1142 / 241$ & 4.88 & $1304 / 197$ & 6.45 & 2446 & 5.58 & $92 / 1175$ & 7.82 & $37 / 1271$ & 2.91 & 5.27 \\
\hline
\end{tabular}

Table 9 Counts and percentages of transgressors according to gender and approximate age groups

\begin{tabular}{|c|c|c|c|c|c|c|}
\hline \multirow[t]{2}{*}{ Age groups } & \multicolumn{2}{|c|}{ Male } & \multicolumn{2}{|c|}{ Female } & \multicolumn{2}{|c|}{ Total } \\
\hline & $\mathrm{N}$ & $\%$ & $\mathrm{~N}$ & $\%$ & $\mathrm{~N}$ & $\%$ \\
\hline School children & 16 & 21.9 & 9 & 16 & 25 & 19.3 \\
\hline Young adults & 33 & 45.2 & 26 & 6.4 & 59 & 45.7 \\
\hline Older adults & 21 & 28.7 & 15 & 26.7 & 36 & 27.9 \\
\hline Elderly & 3 & 4.1 & 6 & 10.7 & 9 & 6.9 \\
\hline Total & 73 & 56.6 & 56 & 43.4 & 129 & 100 \\
\hline
\end{tabular}

Legend The approximate age of transgressors was coded according to five pre-determined age groups as follows: baby/toddler $(0-4$ years old); school children (5-15 years old); young adult/teenager (16-30 years old), older adult (30-70 years old); elderly $(70+$ years old)

\subsubsection{Journey Context and Crossing Pace}

Among all 129 transgressors, 91 were seemingly going to catch a train with most of them $(N=86)$ accessing the train station through a middle island (at Wynnum Central and Coorparoo). The remaining five accessed the station at Cannon Hill either on their way out of a middle platform $(N=2)$, either crossing all LC tracks to access the station on the opposite road side $(N=3)$. Only 66 of all pedestrians going to catch a train appeared to hurry while crossing, while the remaining more than a quarter crossed at a walking pace.

\subsection{Transgressions Associated with Pedestrians' Social Context}

Globally, pedestrians crossing alone (not in groups) accounted for more than three quarters of all transgressions (Table 10). However, there was a significant difference between the three LCs in the number of transgressions while alone, in a group of two, and in a group of more than two pedestrians (Fisher, $p<0.05$ ). The association between the variables was weak $\left(V^{2}=0.03\right)$, with the estimated RDs indicating more likelihood to transgress alone at Cannon Hill, and in groups of two and more pedestrians - at Coorparoo.

\subsection{Transgressions Accounting for the Interactions Between Factors}

\subsubsection{Time of the Day, Moment of Transgression and High Risk Groups of Pedestrians}

The distribution of transgressions in the three moments of controls' activation differed significantly according to the time of the day, $\chi^{2}(2, N=129)=9.98, p<0.01$, with an intermediate association between the variables $\left(V^{2}=0.07\right)$. The estimation of the RDs, revealed that transgressions in morning peak hours were likely to be observed in Moment 1 of the controls' activation, whereas afternoon transgressions were associated with Moment 3. Pedestrians of different age groups also showed significantly different crossing patterns according to the moment of transgression (Fisher, $p<0.05$ ), the association between the variables being also intermediate $\left(V^{2}=0.05\right)$. The RDs associated school children with transgressing before and until the pedestrian gates are closed (Moment 1 and 2), whereas older adults and elderly were associated with transgressing in Moment 2, and younger adults with transgressing in the riskiest Moment 3. On the contrary, there was not a significant difference in the moments of transgression between male and female pedestrians, $\chi^{2}(2$, $N=129)=1.08$, ns.

In contrast, the two genders showed different patterns of transgression according to the time of the day, $\chi^{2}(1$, $N=129)=5.66, p<0.05$, the association between the variables being weak $\left(V^{2}=0.04\right)$. According to the RDs, female pedestrians were more likely to be observed transgressing in the morning, whereas male pedestrians - in the afternoon. Concretely, the odds of observing a male pedestrian transgressing in the afternoon peak hours were 0.37 times higher than observing a female. Pedestrians of different age groups also appeared to be likely to transgress in different times of the day, $\chi^{2}(3, N=129)=8.31$, $p<0.05$. The strength of association between the two 
Table 10 Counts and percentages of transgressions alone and in group of pedestrians

\begin{tabular}{|c|c|c|c|c|c|c|}
\hline & \multicolumn{2}{|c|}{ Alone } & \multicolumn{2}{|c|}{ In group 2 pedestrians } & \multicolumn{2}{|c|}{ In group $3-4$ pedestrians } \\
\hline & $\mathrm{N}$ & $\%$ & $\mathrm{~N}$ & $\%$ & $\mathrm{~N}$ & $\%$ \\
\hline Wynnum Central & 40 & 39.6 & 7 & 6.9 & 2 & 1.9 \\
\hline Cannon Hill & 13 & 12.8 & 1 & 0.9 & 0 & 0 \\
\hline Coorparoo & 27 & 26.7 & 7 & 6.9 & 4 & 3.9 \\
\hline Total & 80 & 79.2 & 15 & 14.8 & 6 & 5.9 \\
\hline
\end{tabular}

variables being intermediate, the estimation of the RDs showed that young adults/teenagers were associated with transgressing in afternoon peak hours, whereas older adults and elderly were associated with transgressions in the morning peak hours $\left(V^{2}=0.06\right)$.

\subsubsection{Train Position, Trajectory and Number of Crossed Tracks}

The number of transgressions was significantly different according to the train's position in interaction with: moment of crossing, time of the day and crossing trajectory. The moment of crossing was strongly associated with train's position, Fisher, $p<0.000, V^{2}=0.27$. The estimation of the RDs showed that transgressions in front of an approaching train were particularly associated with crossing before the gates are closed (i.e. Moment 1 and 2), whereas transgressions in the presence of a visible train (i.e. behind a stopped train and other positions) were strongly associated with Moment 3. In contrast, a weak association between train position and time of the day suggested that transgressions in the presence of a visible train (behind a passing train and other positions) were likely to be observed in afternoon peak hours, Fisher, $p<0.05, V^{2}=0.04$. The adopted trajectory was also weakly associated with train position, $\chi^{2}(4, N=$ 129) $=9.04, p<0.05, V^{2}=0.04$. The estimation of the RDs showed that crossing behind a stopped train was associated with going towards a middle island, whereas other train positions (i.e. crossing behind a passing express or in front of a stopped train) were associated with going out of a middle island.

The adopted transgression trajectories differed significantly according to time of the day, $\chi^{2}(2, N=129)=$ 6.82, $p<0.05, V^{2}=0.05$. According to the estimated RDs, the intermediate relationship between the variables suggested that leaving a middle island and just crossing the road were associated with transgressions in the afternoon peak hours. There was not a significant difference in the adopted trajectories according to the moment of transgression.

The total number of crossed rail tracks during transgression was significantly different according to the Moment of transgression, Fisher, $p<0.05$, the association between the variables being moderate, $V^{2}=0.04$. The RDs revealed that the crossing of more than one rail track (i.e. two or three) was more likely to be observed during the closure of the pedestrian gates (Moment 2), whereas crossing in Moment 3 was associated with crossing one rail track. However, the number of crossed unoccupied tracks was similar independently of the moment of transgression (Fisher, ns.), noting that $11.6 \%$ of the pedestrians crossed one unoccupied track after a first train had passed, taking the potential risk of crossing in front of a second train.

\subsubsection{Crossing Alone and in Group, Demographics and Time of the Day}

There was a significant relationship between transgressions alone or in group and the age of pedestrians $\left[\chi^{2}(3, N=\right.$ 129) $\left.=23.20, p<0.000, V^{2}=0.17\right]$, the adopted crossing trajectory $\left[\chi^{2}(2, N=129)=6.70, p<0.05, V^{2}=0.05\right]$ and the time of the day $\left[\chi^{2}(1, N=129)=4.11, p<0.05\right.$, $\left.V^{2}=0.03\right]$. The strong association with the age groups of participants indicated that school children and elderly were more likely to transgress alone, whereas older adults were more likely to transgress in groups. According to the RDs, the intermediate relationship with the adopted trajectory revealed that transgressing alone was associated with going out of a middle island or just crossing, whereas group transgressions were associated with going towards a middle island. Finally, according to the RDs the weak association with time of the day indicated that group transgressions were more likely to be observed in the morning, whereas pedestrians transgressing alone were associated with afternoon hours.

\section{Discussion}

Pedestrians' unsafe crossing at LCs has been identified as a highly under-researched area lacking notably in the understanding of the key factors influencing decisionmaking of this particular population. This paper presented the results from direct observations conducted at three key black spot LCs in Brisbane, providing novel and contextual relevant evidence on the role of multiple factors 
contributing to risky crossing behaviours. Despite the short duration of the observations, a relatively large number of transgressions $(N=129)$ was observed corresponding to more than $5 \%$ of all pedestrians present at the LCs at the end of the observed closures, noting that information on the moment of their arrival at the LCs was not collected.

The following sections contrast the simple effects of risk factors on unsafe crossing at the three LCs (generalised case) with the effects of the same risk factors on unsafe crossing according to the specific characteristics of the crossing context at each of the three LCs.

\subsection{The Simple Effects of Risk Factors at LCs in Brisbane}

The observed transgressions seemed to differ according to the moment of crossing, the time of the day and the adopted trajectory, which were directly or indirectly associated with different demographic profiles of pedestrians. The links between moment of transgression and other risk factors are described in the following paragraphs, representing thus findings informing on three potential key at risk transgression patterns adopted by pedestrians, users of the Cleveland rail line.

\subsubsection{Transgressions in the First Moments After the Controls' Activation}

In line with previous findings, the largest proportion of transgressions occurred before the gates are closed and even active. Such transgressions were particularly associated with crossing in front of an approaching train (unlikely to be visible), and with transgressions in morning peak hours. In fact, contrary to what has been demonstrated by Edquist, Hughes [7] and Metaxatos and Sriraj [1], the largest proportion of transgressions at all three LCs occurred at morning peak hours and this was even after accounting for the number of pedestrians crossing compliantly during all closures. The observed transgressions in morning peak hours were associated with female pedestrians and school children. Unlike previous findings, school children were linked with crossing alone. The summary of all these simple effects could explain transgressions motivated by a fear of missing the next train and of being late for school. Transgressions before the gates have started moving and in front of an approaching train were consistently associated with crossing towards a middle island. This was globally the predominantly adopted trajectory during all transgressions potentially related to the motivation of catching the next train as was visible in $70 \%$ of the cases, noting that the journey purpose was not identifiable for all transgressions.

\subsubsection{Transgressions During the Closure of the Pedestrian Gates}

A larger number of pedestrians were observed transgressing once the gates were fully closed compared to while they were closing. Such findings are in contradiction with "beating the gates" tendencies and the obtained results by Metaxatos and Sriraj [1]. Nevertheless, the results from these observations associated older adults and elderly with crossing during gate closure and with afternoon peak hours. Older adults were associated with crossing in groups and elderly associated with crossing alone. The combination of these results could explain an increased perception of control (e.g. "I could make it on time") before the gate is fully closed, rather than sensation seeking tendencies.

\subsubsection{Transgressions After the Closure of the Pedestrian Gates}

Crossing after the gates are closed was also associated with afternoon peak hours and with the presence of a visible train (stopped or passing through). Crossing in this last moment of the activation of controls was common to young adults/teenagers, who themselves were also associated with crossing in the afternoon peak hours. Transgressions of young adults/teenagers in afternoon peak hours corresponded to crossing out of a middle island or just crossing. All these results taken together could be associated with impatience to wait for the controls to deactivate after disembarking from a train in the afternoon peak hours, potentially taking the risk of crossing in front of a second train. Examining the risk of crossing in front of a second train according to the number of crossed unoccupied rail tracks, no significant difference was found according to the moment of transgression, meaning that independently of the moment of transgression, pedestrians were equally likely to cross one or more unoccupied potentially "at risk" of second train tracks. Similarly, transgressing after the gates are closed was strongly associated with the crossing of one rail track, most likely after a train has passed the LC, which could explain a certain awareness of the risk of second train. Still, in total, a large number of pedestrians crossed one unoccupied track after the gates were closed (11.6\%) embracing the risk of crossing in front of a second train. Taken together, these results suggest that crossing once the gates are fully closed is highly influenced by the train's visibility and is indeed a serious potential threat for crossing in front of a second train. Being associated with younger adults, such risk-taking behaviours could be explained by the perception of control or familiarity with the LC design and rail traffic. It could also be explained by sensation seeking tendencies or "recreational" risk-taking in the late afternoon peak hours. It would be worth looking 
further into the patterns of transgressions according to whether one or both sides of the middle island were closed during transgression in front of a second train. Such evidence would contribute to a better understanding of the pros and cons of having a separate regulation of pedestrian traffic at both sides of a middle island, especially in the case that there is a train station on the middle island.

\subsection{The Effects of Interacting Factors Associated with the Crossing Context at Three Typical Black Spot LCs Within Brisbane Area}

Different transgression patterns across the three LCs were identified depending on the characteristics of the larger area, the LC and station environment, as well as according to rail traffic characteristics. The largest number of pedestrians crossing compliantly and transgressions were counted at Wynnum Central, the second most populated suburb, giving access to the train station through a middle island where crossing is prohibited along the pedestrian corridors for each train passage independently of its direction. In contrast, the largest proportion of transgressions accounting for the total number of people crossing during closures was observed at Coorparoo, the most populated suburb where the total number of people crossing compliantly and transgressing was lower compared to Wynnum Central. Having a similar design comprising the train station at a middle island, the main difference between Coorparoo and Wynnum Central is the presence of a third track and the separately operated pedestrian corridors on the two sides of the middle island at Coorparoo. On the contrary, Cannon Hill was the least populated suburb with the lowest number of pedestrians observed to cross compliantly and transgressing at this LC not giving access to the train station but to a middle platform separating the three tracks. Contrary to previous findings, the location of the platforms outside of the rail tracks was not associated with a larger number of transgressions. However, a more in depth analysis of the results revealed that at Cannon Hill pedestrians were observed to take the most risk by crossing the largest number of rail tracks where a train could have passed (unoccupied tracks).

\subsubsection{Transgression Patterns Related to the Crossing Context at Wynnum Central}

Transgressions at Wynnum Central were associated with crossing in the last moment of controls' activation, with the presence of a visible-stopped or passing train (i.e. the majority observed behind a stopped at station train) and with afternoon peak hours. At this site, pedestrians crossing right after the train has passed the LC (City train) could still catch it from the station. Such transgressions behind a stopped train and after the gates are closed were also associated with younger adults. Moreover, in the afternoons more transgressions were observed in groups. Wynnum Central stood out as the LC where most variability was observed in the adopted trajectories towards the station. A large number of transgressors came from the large shopping Centre side and crossed on diagonal or even through the centre of the LC. Crossing on diagonal could be explained by the motivation to avoid waiting to cross at a nearby intersection with four pairs of pedestrian traffic lights connecting the different sides of the road (Fig. 3). The large number of transgressions from either side of the crossing could be associated with catching the City Train service (i.e. if crossing behind a stopped train). For those transgressing from the Centre side of the LC, being in a hurry to catch the City train implies crossing through the Outbound track. If pedestrians are familiar with such crossing situation, they can easily assume that even if there is an approaching second train (coming from the City) it will stop at station before reaching the LC platform. However, in reality an express train could be approaching anytime at full speed. Consequently, it can be argued that the simultaneous regulation of pedestrian traffic on both sides of a middle island could lead people to underestimate the risk of second train arrival even it is visible. Such risk could potentially be avoided if pedestrians were to use the existing over bridge that provides access to the platforms from the car park. However, pedestrians might be unlikely to cross the overbridge given its distant location from the main road, which is a main adopted trajectory if coming from the shopping centre. Consequently, a more adequate location of the over bridge or a separate regulation of both tracks at this LC could potentially minimise the risk of transgressions and especially - in front of a second train.

\subsubsection{Transgression Patterns Related to the Crossing Context at Cannon Hill}

Cannon Hill was associated with transgressions before the gates have started closing (Moment 1). Transgressions in the first moments were predominantly observed in morning peak hours, in front of an approaching train and by school children. School children were likely to be seen crossing alone and so were in general transgressors observed in the morning peak hours. Contrary, to previous findings the location of the train station externally to the rail tracks was associated with a lower number of transgressions compared to the other two LCs. However, looking into the adopted trajectories a strong pattern of transgressions was identified, corresponding to the crossing of multiple tracks to access the station (City train service platform), including crossing the road and going out of a middle island. In fact, among the three LCs, only Cannon Hill was associated 
with just crossing the road or exiting the middle platform, trajectories corresponding to the emplacement of the train station at this particular site externally to the rail tracks. While the existing over bridge linking the middle island platform and the train station could have contributed to decrease transgressions, the separation of the third track from the passenger services tracks could potentially be associated with an increased level of risk during transgressions as pedestrians crossing through the passenger services corridor are obliged to cross both tracks at the same time.

\subsubsection{Transgression Patterns Related to the Crossing Context at Coorparoo}

Finally, Coorparoo was associated with crossing before the pedestrian gates are fully closed (Moment 2). Transgressions in this moment were predominantly observed in afternoon peak hours and by older adults and elderly. Moreover, Coorparoo was mostly associated with crossing in groups of two and more pedestrians, noting that group transgressions were also associated with older adults and with crossing towards a middle island. Coorparoo was also the only LC associated at the same time with crossing none (not at risk) and two unoccupied tracks. Thus in addition to the trajectory corresponding to crossing from either side to catch a City train, pedestrians at Coorparoo also transgressed on their way out of the middle island after disembarking a train. Thus, this LC seems to be associated with two different transgression patterns: one describing transgressing in groups to catch a train, and one crossing towards a car park in the afternoon hours (Fig. 5). Indeed, the diagonal transgression towards the LC's angle without a pedestrian path could explain the motivation to avoid waiting at pedestrians' road traffic lights on the way to a nearby smaller car park (not illustrated on Fig. 5). Compared to Wynnum Central where the station is also on the middle island, at Coorparoo more transgressions occurred on the City train rail track than on the Outbound rail track. Therefore, the introduction of an external platform similarly to Cannon Hill could help improving the safety of City train passengers.

\section{Limitations and Future Perspectives}

A number of limitations can be addressed to the collected data and the adopted observations method. The presence of observers could unduly influence participants' behaviour. Indeed, it is possible that pedestrians have refrained from transgression in the presence of observers. Moreover, given that there is a legal sanction for crossing at red signal, such bias should not be underestimated. In terms of the adopted procedure, data could not be considered as representative to the larger Queensland area, as the observations were conducted at only three LC sites and the data collection period was limited. Nevertheless, the results give an approximate indication on the number and proportion of transgressions at each LC site, given that observation sessions lasted for five hours per day. Also, the method facilitated gathering a detailed body of data, including description of potential risk prone crossing situations at LCs part of the riskiest Brisbane railway line, although not exhaustive. For instance, no indication was collected on the patterns of behaviour out of the two peak time zones. In addition, an estimation of the size of pedestrian flow, not only during the closures, would enhance the understanding of the proportion of transgressors among pedestrians crossing compliantly. Furthermore, a more in depth analysis of the characteristics of the respective populations at the three LC sites would enhance the understanding of high risk groups of pedestrians. Video data could provide complementary information on the proportion of transgressors compared to compliant pedestrians from each demographic group, and is therefore a potential path for future research. Moreover, the interactions between multiple factors could be further tested in simulation studies with the possibility to recreate various realistic crossing situations. Such studies are likely to provide a more in depth explanation of the precursors of behaviour and would therefore enhance the development of more effective safety measures (be it through safety campaigns aiming at the reduction of motivational factors, be it through updates of the environment improving pedestrian traffic conditions). Moreover, simulation studies would allow to pre-test the effects of already identified risk factors on a wider range of crossing situations (e.g. passive LCs, different active or passive controls).

\section{Conclusion}

The interactions between different factors were examined, contributing to the better understanding of the larger pedestrian crossing context likely to be influenced at the same time by the environmental properties of the LC, by personal motivations and characteristics of pedestrians themselves or else, by the presence of other individuals. As opposed to a large part of previous studies' emphasising on a single factor's contribution to unsafe crossing, this analysis of the interactions between factors illustrates potential highly "at risk" crossing situations, taking into consideration similarities and differences across typical for the area LC designs and socio-economic contexts. Arguably, the discussed interactions between risk-contributing factors suggest that independently of the LC site and its design, transgressions correspond to the fastest and most 
convenient path of accessing the platforms in order to catch a train. However, the analysis of the specific crossing context also reveals that such transgressions can be associated with a different level of risk-taking. In addition, transgressors at the three observation sites adopted different crossing trajectories likely to be associated not only with the design of each LC in terms of the location of the platforms and rail tracks, but also with characteristics of the larger area, notably in relation to the provided access points to the station's platforms. Thus, arguably, the role of characteristics of the larger area, such as the presence of car parks, road traffic lights, over bridges and main roads are often underestimated as potential risk-contributing factors to pedestrian crossing. Therefore, to improve safety, each LC environment should be optimised according to the characteristics of the area and the population.

Acknowledgments The authors are grateful to the CRC for Rail Innovation (established and supported under the Australian Government's Cooperative Research Centres program) for the funding of this research. Project No. R2.120: Understanding Pedestrian Behaviour at Level Crossings. The authors would like to thank Queensland Rail for their permission to conduct this study at the three selected level crossing sites. The authors would also like to thank all train stations' rail staff for their cooperation and diligence. The authors are grateful to Julian Pearce, Laurel English, Michael Leo and Wanda Griffin for their outstanding performance as assistant observers.

Open Access This article is distributed under the terms of the Creative Commons Attribution 4.0 International License (http://crea tivecommons.org/licenses/by/4.0/), which permits unrestricted use, distribution, and reproduction in any medium, provided you give appropriate credit to the original author(s) and the source, provide a link to the Creative Commons license, and indicate if changes were made.

\section{Appendices}

\section{Appendix 1}

Transgressions observation sheet

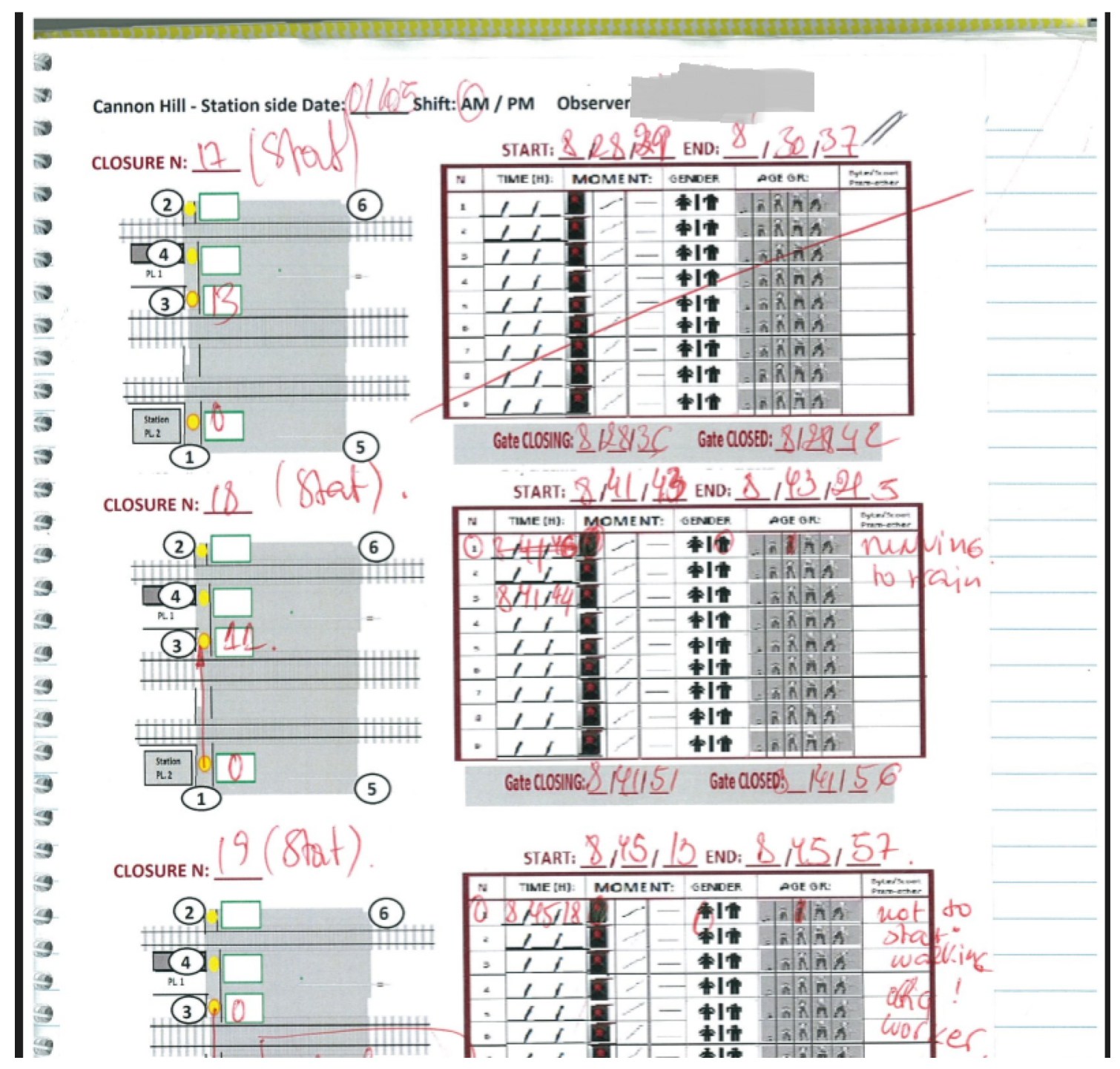




\section{Appendix 2}

Train times observation sheet

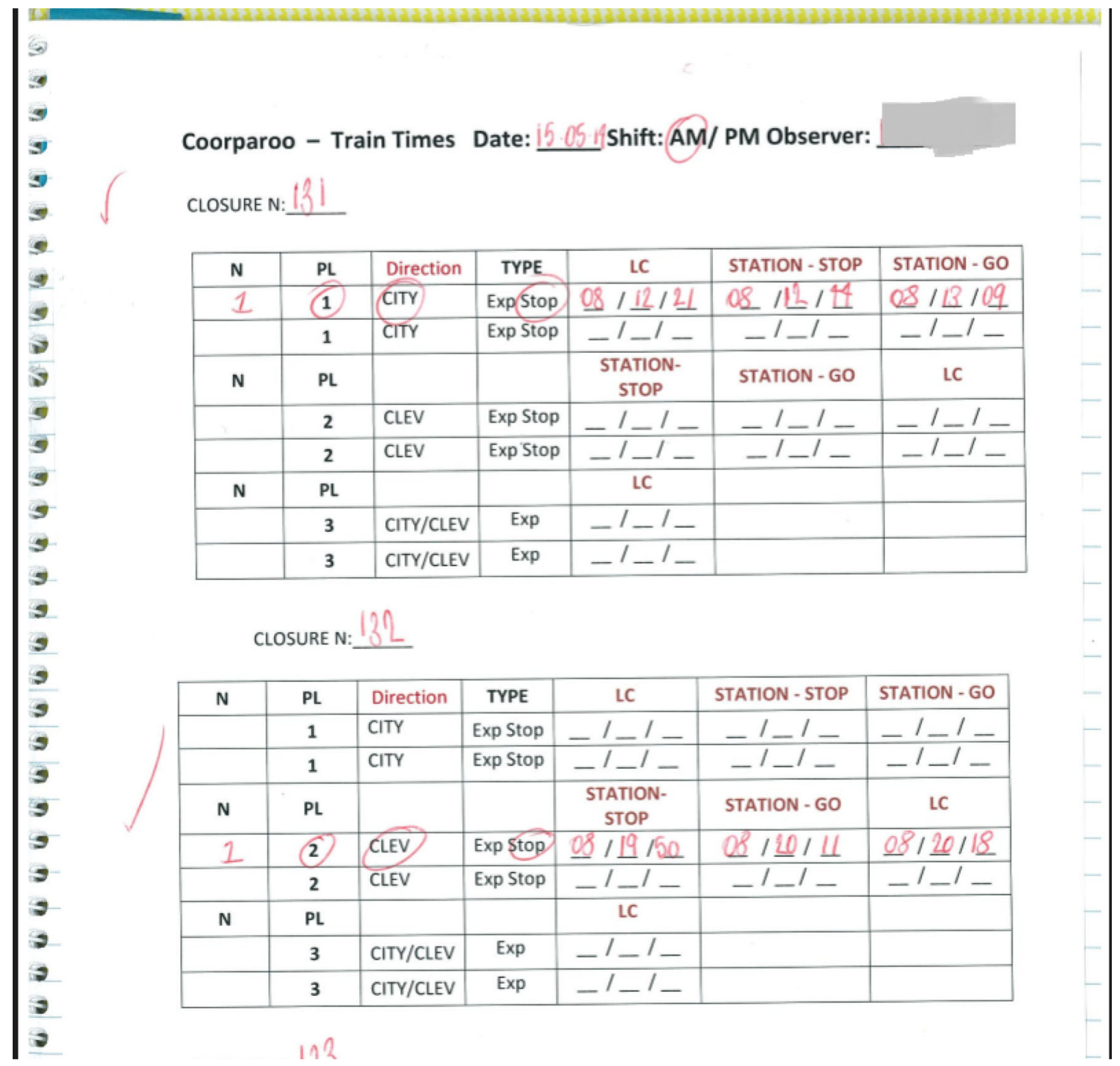

\section{References}

1. Metaxatos P, Sriraj PS (2013) Pedestrian/bicyclist warning devices and signs at highway-rail and pathway-rail grade crossings in civil enginneering studies. Illinois Center for Transportation Series, Illinois

2. ATSB (2012) Australian rail safety occurrence data 1 July 2002-30 June 2012 in Australian rail safety occurrence data. Australian Transport Safety Bureau, Canberra, p 48

3. Queensland Rail (2012) Level crossings near miss table (2011). Queensland Rail website, Brisbane

4. Iorio L, De Marco S, Cosciotti E (2012) Life momentum at level crossing: human factor, road-rail safety policies, available technologies. A cross-sectorial challenge playing a rewarding role for the upgrade of safer mobility options, in Global Level Crossing and Trespass Symposium 2012. London
5. Edquist J et al (2009) A literature review of human factors safety issues at Australian level crossings. MUARC, Melbourne

6. Stefanova $T$ et al (2015) System based approach to investigate pedestrian behaviour at level crossings. Acc Anal Prev 81:167-186

7. Edquist J, Hughes B, Rudin-Brown CM (2011) Pedestrian non compliance at level crossing gates. CURTIN-Monash accident research centre, Perth

8. Khattak A, Luo Z (2011) Pedestrian and bicyclist violations at highway-rail grade crossings. Transportation research record. J Transport Res Board 2250(1):76-82

9. McPherson C, Daff M (2005) Pedestrian behaviour and the design of accessible rail crossings. 28th Australian Transport Research Forum, Sydney

10. Parker A (2002) Second train coming warning sign demonstration projects. In: Administration FT (ed) Transportation Research Board of the National Academies. p 39 
11. Sposato S, Bien-Aime P, Chaudhary M (2006) Public education and enforcement research study in safety of highway-railroad grade crossings series 2006. U.S Department of transportation, Federal Railroad Administration, p 110

12. Stewart S, Brownlee R, Stewart D (2004) Second train warning at grade crossingsIn: Canada $\mathrm{T}$ (ed) Transportation Development Centre, p 103

13. Basacik D, Cynk S, Flint T (2012) Spotting the signs: situation awareness at level crossings, in Global Level Crossing and Trespass Symposium, London

14. Clancy J, Kerr W, Scott M (2006) Study of pedestrian behaviour at public railway crossings. Lloyd's Register Rail Limited

15. Clancy J, Dickinson S, Scott M (2007) Study of pedestrian behaviour at public railway crossings. Lloyd's Register Rail Limited
16. Clark HE, Perrone JA, Isler RB (2013) An illusory size-speed bias and railway crossing collisions. Acc Anal Prev 55:226-231

17. Khattak A (2009) Comparison of driver behavior at highwayrailroad crossings in two cities. Transportation research record. J Transport Res Board 2122(1):72-77

18. Wullems C, Toft Y, Dell G (2013) Improving level crossing safety through enhanced data recording and reporting: the CRC for rail innovation's baseline rail level crossing video project. Proceedings of the institution of mechanical engineers, Part F. J Rail Rapid Transit 227(5):554-559

19. Kotrlik JW, Williams HA, Jabor MK (2011) Reporting and interpreting effect size in quantitative agricultural education research. J Agric Educ 52(1):132-142 